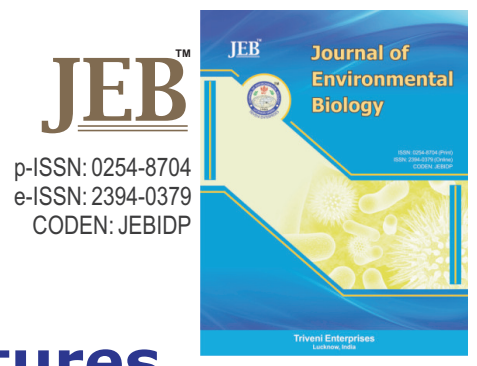

\title{
Effect of alternating temperatures on food utilization of tomato fruit borer, Helicoverpa armigera
}

\section{Authors Info \\ P.K. Dalal* and R. Arora \\ Department of Entomology, Punjab Agricultural University, Ludhiana- 141 004, India \\ *Corresponding Author Email : pradeepdalalag@gmail.com}

Key words

Alternating temperature Digestibility

Food utilization

Helicoverpa armigera

Tomato fruit borer

Publication Info

Paper received : 17.04 .2017

Revised received : 07.09.2017

Re-revised received : 28.11.2017

Accepted : 02.01.2018

\section{Abstract}

Aim : The following study was undertaken to record the trend of approximate digestibility and efficiency of conversion of ingested food into body substance during larval stage of tomato fruit borer, Helicoverpa armigera (Hübner) due to rise in alternating temperatures.

Methodology : The experiment was conducted under digitally controlled walk-in-type plant growth chamber. The impact of six alternating temperatures (Max : Min) viz. 25:10, 25:13, 25:16, 30:10, 30:13 and $30: 16^{\circ} \mathrm{C}$ were studied on approximate digestibility and efficiency of conversion of ingested food into body substance of three final larval instars of $H$. armigera on tomato crop. Various observations like food consumption, weight of feces and larval insect were recorded daily till pre-pupal stage and recorded data were used in mathematical equations to calculate approximate digestibility and efficiency of conversion of ingested food into body substance.

Results : Both, approximate digestibility and efficiency of conversion of ingested food into body substance values responded with respect to change in alternating temperatures. Approximate digestibility values followed an increasing trend from 8.675 to $31.432 \%$ with increase in temperature from $25: 10$ to $25: 16^{\circ} \mathrm{C}$. The increasing trend of approximate digestibility continued with rise in temperature from 30:10 to $30: 16^{\circ} \mathrm{C}$. However, efficiency of conversion of ingested food into body substance values declined gradually from 14.993 to $9.371 \%$ with rise in temperature from $25: 10$ to $30: 16^{\circ} \mathrm{C}$.

Interpretation: The study suggest that in the event of rising temperature under climate change, $H$. armigera would better digest the tomato fruit but would be less efficient to convert ingested tomato fruit into body substance.

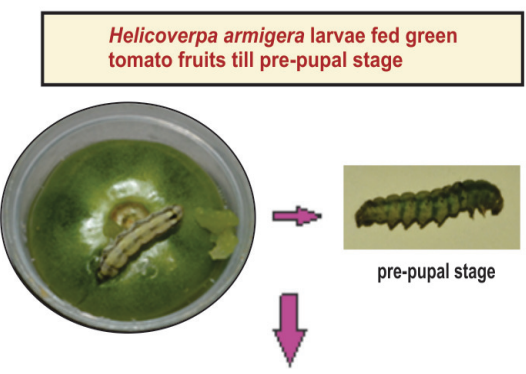
$14 \mathrm{hrs}$ (Light) $10 \mathrm{hrs}$ (Dark) $25^{\circ} \mathrm{C}$ $\$ 0^{\circ} \mathrm{C}$ $10 \mathrm{C}$

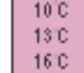

Six alternating temperature as treatments

$25: 10^{\circ} \mathrm{C} 25: 13^{\circ} \mathrm{C} 25: 16^{\circ} \mathrm{C} 30: 10^{\circ} \mathrm{C} 25: 13^{\circ} \mathrm{C} 25: 16^{\circ} \mathrm{C}$ \ל

Nutritional indices like approximate digestibility and efficiency of conversion of ingested food recorded

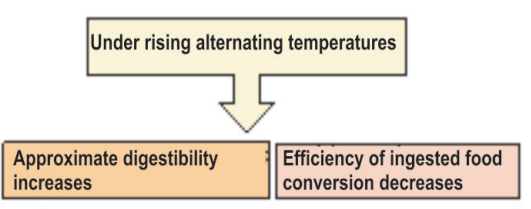

Under rising temperatures, $H$. armigera digests tomato fruit better but less efficient in converting ingested food into body substance Maximum temperature Minimum temperature 


\section{Introduction}

Globally ambient temperature is breaking all records year after year. In all possibilities, the global mean temperature is expected to exceed $1.5^{\circ} \mathrm{C}$ compared to pre-industrial level (18501900 ) by 2100 (IPCC, 2014). Punjab state in India has also witnessed slow and steady rise in minimum temperature by $0.06^{\circ} \mathrm{C}$ per year over the past four decades (Kaur et al., 2012). Increased temperature under changing climate regime will have a major bearing on survival of ectothermic organism like insects (Akbar et al., 2016). Also, temperature affects directly by stimulating insect feeding and development and indirectly by changing the biochemical composition of host plant (Ayers and Scriber, 1994; Yuan et al., 2009). As the temperature rises the metabolic demands of the insects increase exponentially, as a result the insects likely to fulfill these demands by means of increased food consumption (O'Connor, 2009). Scriber and Slansky (1981) reported that cyclic or variable temperature regimes affect the utilization of food in most insect herbivores. This suggests that utilization of consumed food also likely to vary with rise in temperature.

Helicoverpa armigera (Hübner) (Lepidoptera: Noctuidae) is highly polyphagous and widely distributed insect pest which has recently extended its range from Europe, Africa, Asia and Australia to some countries in South and Central America (Fitt, 1989; Kriticos et al., 2015). H. armigera is variously named as gram pod borer, American bollworm and tomato fruit borer due to its damage on chickpea, cotton and tomato crops. It attacks a total of 156 host plants from 41 families of angiosperms and among the various plants, tomato is listed as a major host (Manjunath et al., 1989). It is estimated that $H$. armigera alone is responsible for global loss of over US $\$ 2.0$ billion annually, excluding socioeconomic and environmental costs associated with its control (Tay et al., 2013). The tomato fruit borer, $H$. armigera is one of the major biotic constraints in the quality tomato, Solanum lycopersicum production. The pest is active throughout the year and prefers to feed on the floral bodies of its host plants (Meena and Raju, 2014). The avoidable yield losses caused by $H$. armigera in tomato crop has been reported to be $31.53 \%$ (Singh et al., 2017). The recent report suggests that under increased temperature condition $\mathrm{H}$. armigera consumes more tomato fruits (Dalal and Arora, 2016). The food ingested by insect herbivores undergo digestion and utilization by means of converting it into body substance. The investigation on utilization of host by insect becomes significant as it gives indirect measurements of relative susceptibilities and attributes of host plant to insect performance and infestation (Slansky, 1990; Praveen and Dhandapani, 2001). To understand the insect plant relationship under environmental stress including rising temperature, the studies on utilization of food are of fundamental importance (Bhat and Bhattacharya, 1978). Keeping in view the recent events in the rise of temperature and insufficient knowledge of its impact on insect plant relationship, an attempt was made to obtain information on the effect of rise in alternating temperature on food utilization of $H$. armigera on tomato crop.

\section{Materials and Methods}

The present study was carried out in a walk-in-type climatic chamber (PGW 40, Percival Scientific Company, USA) and at the Entomological Research Farm, Department of Entomology, Punjab Agricultural University, Ludhiana. For raising tomato crop, the seeds of tomato genotype US-8502 (Ujjawal Seeds Pvt. Ltd., Delhi) were obtained from the local market and raised in the medium size earthen pots (height $21 \mathrm{~cm}$, diameter 24 $\mathrm{cm}$ ) and thereafter transplanted in the field as per recommended package of practices (Anonymous, 2013). But no insecticides were applied to the crop for management of any insect pest. Larvae of $H$. armigera were collected from tomato field and were used to establish the laboratory culture of the insect. All the larvae were reared in specimen tubes $(37 \times 50 \mathrm{~mm})$ singly and the culture was maintained at controlled temperature of $25 \pm 1^{\circ} \mathrm{C}$ in the plant growth chamber (PGW 40, Percival Scientific Company, USA). A semi-synthetic diet after Armes et al. (1992) was used for rearing larval culture.

The sexing of pupae were carried out for identification of male and female of $\mathrm{H}$. armigera according to the method of Paul et al. (1979) before the emergence of adult moths. Two pairs of newly emerged male and female moths were released inside the oviposition chamber made from a simple earthen pot with a hole at the bottom (Arora and Battu, 1996). The top of the pot was covered with a muslin cloth, which was changed daily to obtain fresh eggs. A small quantity of water was added everyday to the plastic tub to maintain water level in the pot. Extreme hygienic conditions were maintained and $0.025 \%$ sodium hypochlorite solution was used for surface sterilization of eggs of $H$. armigera laid on muslin cloth (Rabindra et al., 1997). Muslin cloth containing eggs were kept in a glass jar $(20 \times 15 \mathrm{~cm})$ at the base of which a moistened disc of foam was placed to prevent desiccation of eggs. The eggs were kept in these glass jars $(20 \mathrm{~cm} \times 15 \mathrm{~cm})$ till the emergence of neonates which were further separated by means of camel hair brush. The neonates emerging from eggs were used for further experimentation. A total of six alternating temperature regimes (max:min) were selected as treatments $\left(T_{1}\right.$ $25: 10^{\circ} \mathrm{C}, \mathrm{T}_{2}-30: 10^{\circ} \mathrm{C}, \mathrm{T}_{3}-25: 13^{\circ} \mathrm{C}, \mathrm{T}_{4}-30: 13^{\circ} \mathrm{C}, \mathrm{T}_{5}-25: 16^{\circ} \mathrm{C}, \mathrm{T}_{6}-$ $\left.30: 16^{\circ} \mathrm{C}\right)$ at a constant relative humidity $(65 \pm 5 \%)$ along with 14:10 L: D photoperiod. Each treatment was replicated four times. Fifty larvae were kept in plastic tubes $(37 \mathrm{~mm} \times 50 \mathrm{~mm}$ ) at the rate of five neonates per tube at each temperature and were provided tomato leaf discs of $2 \mathrm{~cm}$ diameter as fresh food. The excreta and uneaten food were removed daily and fresh food was provided daily. Similarly, set of additional larvae was maintained. Whenever any of the test larvae died, a larva from additional set was added to replace it so that the number of larvae in each replication remained the same. After 4 days of larval development, these larvae were provided green fruits of tomato and kept similarly till 
Table 1 : Effect of various alternating temperatures on approximate digestibility of $H$. armigera larvae on green tomato fruits

\begin{tabular}{|c|c|c|c|c|}
\hline \multirow[t]{2}{*}{ Temperature $^{\circ} \mathrm{C}$ (Max:Min) ${ }^{*}$} & \multicolumn{3}{|c|}{ Approximate digestibility (\%): Mean \pm SE } & \multirow[b]{2}{*}{ Total feeding period } \\
\hline & Third instar & Fourth instar & Fifth instar & \\
\hline $25: 10(18.75)^{* *}$ & $63.782 \pm 1.767 a$ & $7.640 \pm 1.090 \mathrm{a}(15.9228)^{* * *}$ & $19.952 \pm 1.042 \mathrm{bc}(26.4970)^{\star \star *}$ & $8.675 \pm 1.079 \mathrm{a}(16.9922)^{* * *}$ \\
\hline $25: 13(20.00)$ & $63.761 \pm 1.098 a$ & $11.803 \pm 0.532 b(20.072)$ & $8.145 \pm 2.664 a(16.0557)$ & $8.868 \pm 2.168 \mathrm{a}(16.9308)$ \\
\hline 25:16 (21.25) & $62.476 \pm 0.566 \mathrm{a}$ & $37.889 \pm 0.951 d(37.9722)$ & $24.882 \pm 0.084 c(29.9102)$ & $31.432 \pm 0.874 c(34.0785)$ \\
\hline $30: 10(21.67)$ & $62.893 \pm 1.459 a$ & $30.366 \pm 0.388 \mathrm{c}(33.4246)$ & $16.664 \pm 0.395 b(24.0792)$ & $19.600 \pm 0.608 a b(26.259)$ \\
\hline $30: 13(22.91)$ & $64.216 \pm 0.156 a$ & $32.536 \pm 0.409 \mathrm{c}(34.7631)$ & $32.125 \pm 1.224 d(34.5018)$ & $21.048 \pm 1.121 b c(26.6647)$ \\
\hline $30: 16(24.17)$ & $61.564 \pm 0.102 a$ & $13.519 \pm 0.137 \mathrm{~b}(21.4608)$ & $48.931 \pm 0.059 \mathrm{e}(44.3700)$ & $46.298 \pm 0.209 d(42.8589)$ \\
\hline
\end{tabular}

Means sharing similar letters are not significantly different by Tukey's HSD Test at $P=0.05 ;{ }^{*}$ These temperatures were maintained for $14: 10 \mathrm{hr}$ along with $\mathrm{L}:$ D photoperiod; **Figures in parentheses represent mean value of temperature; ***Figures in parentheses are angular transformed values

the pupal stage. Changing of instars of $H$. armigera was observed from the removed head capsule and exuvia of previous instar which helped in recording feeding duration of different instars. Feeding period did not include the day of moulting and pre-pupal period as the larvae do not consume food during these phases. Observations on weight of fresh food, weight of uneaten food, weight of excreta and fresh weight of surviving larvae were recorded daily with the help of a digital weighing balance (sensitivity $0.1 \mathrm{mg}$ ) from third instar of $H$. armigera larvae to prepupal stage. A parallel set was maintained to estimate the natural loss of moisture from green tomato fruit when kept in specimen tubes $(37 \times 50 \mathrm{~mm}$ ) under similar conditions without larvae to calculate the corrected weight of consumed leaves. This corrected food consumption values was further utilized to calculate the nutritional indices viz., approximate digestibility and efficiency of conversion of ingested food into body substance on fresh weight basis. The corrected weight of food consumption and nutritional indices were calculated by the formula given below (Waldbauer, 1968).

Corrected weight of consumed food $=(1-a / 2)[\mathrm{w}-(\mathrm{L}+\mathrm{bL})]$

Where, $W=$ Weight of food introduced; $L=$ Weight of uneaten food; $a=$ Ratio of weight loss to the initial weight of the food; $b=$ Ratio of weight loss to the final weight of the food; Approximate Digestibility $=F-f / F \times 100$ and Efficiency of conversion of ingested food = G/F x100; Where, $F=$ Corrected weight of food ingested; $\mathrm{G}=$ Fresh weight gain of the insect during feeding period and $\mathrm{f}=$ Fresh weight of feces

The significant difference between treatment means with respect to approximate digestibility, efficiency of conversion of ingested food into body substance of $\mathrm{H}$. armigera in different larval instars were analyzed with SPSS 16.0 software and means were compared by Tukey's HSD.

\section{Results and Discussion}

Approximate digestibility : Approximate digestibility values indicate the degree of digestibility of host plant by an insect herbivore. Higher values of approximate indicate better digestibility of host by an insect herbivore. The perusal of the approximate digestibility values (Table 1 ) of $H$. armigera reared on green tomato fruits at different alternating temperatures revealed that the values of approximate digestibility ranged during third instar (64.216-61.564\%) were correspondingly higher than the range of approximate digestibility during fourth (7.640-37.889\%) and fifth instar (8.145-48.931\%). Similar trend was recorded by Kouhi et al. (2014) in $\mathrm{H}$. armigera on different tomato cultivars, where approximate digestibility values decreased with subsequent instars. Sidhu and Arora (2011) also observed the higher approximate digestibility values in third instar larvae of $\mathrm{H}$. armigera feeding on different rabi forage legumes as compared to fourth and fifth instar larvae. The decline in approximate digestibility values with subsequent instars is often associated with young instar larvae consuming more digestible tissue of the food whereas later instars undergo less selective feeding involving consumption of higher proportion of indigestible fiber (Ansari et al., 2012; Scriber and Slansky, 1981; Soo Hoo and Fraenkle, 1966). However, the rising alternating temperatures $\left(25: 10\right.$ to $\left.30: 16^{\circ} \mathrm{C}\right)$ had no significant effect on approximate digestibility values $\left(64.216 \%\right.$ at $30: 13^{\circ} \mathrm{C}$ to $61.564 \%$ at $\left.30: 16^{\circ} \mathrm{C}\right)$ of third instar. Although, the rising alternating temperature had a marked effect on approximate digestibility values of fourth, fifth instar and total larval feeding period. In the fourth instar, the lowest approximate digestibility value $(7.640 \%)$ was recorded at the lowest alternating temperature $\left(25: 10^{\circ} \mathrm{C}\right)$ having a feeding period of 3.25 days (Table 3). It increased significantly to $11.803 \%$ at $25: 13^{\circ} \mathrm{C}$ and further to $37.889 \%$ at $25: 16^{\circ} \mathrm{C}$. The approximate digestibility values of $30.366 \%$ and $32.536 \%$ recorded at $30: 10^{\circ} \mathrm{C}$ and $30: 13^{\circ} \mathrm{C}$ were at par with each other. At the highest alternating temperature of $30: 16^{\circ} \mathrm{C}$, the approximate digestibility value declined to $13.519 \%$. In the fifth instar, the approximate digestibility values varied from $8.145 \%\left(25: 13^{\circ} \mathrm{C}\right)$ to $48.931 \%$ $\left(30: 16^{\circ} \mathrm{C}\right)$. Taking the total feeding period from third to fifth instar into consideration, the lowest approximate digestibility values of $8.675 \%$ and $8.868 \%$ were recorded at two lower alternating temperatures of $25: 10^{\circ} \mathrm{C}$ and $25: 13^{\circ} \mathrm{C}$, respectively. The highest approximate digestibility value of $46.298 \%$ was recorded at the highest alternating temperature $\left(30: 16^{\circ} \mathrm{C}\right)$. The approximate digestibility value $(46.298 \%)$ for the total feeding period of 8.75 
Table 2 : Effect of various alternating temperatures on efficiency of conversion of ingested food of $H$. armigera larvae on green tomato fruits

\begin{tabular}{lllll}
\hline Temperature $^{\circ} \mathrm{C}$ (Max:Min) & & \multicolumn{2}{l}{ Efficiency of ingested food conversion (\%): Mean \pm SE } & \\
\cline { 2 - 5 } & Third instar & Fourth instar & Fifth instar & Total feeding period \\
\hline $25: 10(18.75)^{* *}$ & $26.091 \pm 0.731 \mathrm{~b}(30.6975)^{* * *}$ & $43.983 \pm 1.491 \mathrm{e}(41.5232)^{* * *}$ & $9.857 \pm 0.328 \mathrm{c}(18.2843)^{* * *}$ & $14.993 \pm 0.797 \mathrm{~d}(22.7716)^{* * *}$ \\
$25: 13(20.00)$ & $56.976 \pm 0.764 \mathrm{e}(48.9915)$ & $32.922 \pm 1.773 \mathrm{~d}(34.9797)$ & $10.375 \pm 0.343 \mathrm{c}(18.7761)$ & $14.905 \pm 0.055 \mathrm{~d}(22.7005)$ \\
$25: 16(21.25)$ & $39.297 \pm 0.343 \mathrm{c}(38.8031)$ & $13.458 \pm 0.364 \mathrm{a}(21.5075)$ & $7.842 \pm 0.251 \mathrm{~b}(16.2510)$ & $12.462 \pm 0.245 \mathrm{c}(20.6611)$ \\
$30: 10(21.67)$ & $52.271 \pm 0.657 \mathrm{~d}(46.2827)$ & $26.282 \pm 0.833 \mathrm{c}(30.8206)$ & $8.050 \pm 0.108 \mathrm{~b}(16.4751)$ & $12.791 \pm 0.089 \mathrm{c}(20.9473)$ \\
$30: 13(22.91)$ & $25.874 \pm 0.889 \mathrm{~b}(30.5625)$ & $12.314 \pm 0.857 \mathrm{a}(20.5013)$ & $10.527 \pm 0.642 \mathrm{c}(18.9008)$ & $11.478 \pm 0.115 \mathrm{~b}(19.7940)$ \\
$30: 16(24.17)$ & $19.687 \pm 0.556 \mathrm{a}(26.3226)$ & $18.948 \pm 0.196 \mathrm{~b}(25.7925)$ & $4.688 \pm 0.013 \mathrm{a}(12.4998)$ & $9.371 \pm 0.256 \mathrm{a}(17.8151)$ \\
\hline
\end{tabular}

Means sharing similar letters are not significantly different by Tukey's HSD Test at $P=0.05$; ${ }^{*}$ These temperatures were maintained for $14: 10 \mathrm{hr}$ along with L: D photoperiod; **Figures in parentheses represent mean value of temperature; ${ }^{* * *}$ Figures in parentheses are angular transformed values

Table 3 : Effect of various alternating temperatures on feeding period of $H$. armigera on green tomato fruits

\begin{tabular}{|c|c|c|c|c|}
\hline \multirow[t]{2}{*}{ Temperature $^{\circ} \mathrm{C}$ (Max:Min) } & \multicolumn{4}{|c|}{ Feeding period (Days): Mean \pm SE } \\
\hline & Third instar & Fourth instar & Fifth instar & Total feeding period* \\
\hline $25: 10(18.75)$ & $3.25 \pm 0.25 a$ & $3.75 \pm 0.25 a$ & $7.75 \pm 0.48 c$ & $14.75 \pm 0.48 \mathrm{c}$ \\
\hline $25: 13(20.00)$ & $2.75 \pm 0.25 a$ & $3.75 \pm 0.25 a$ & $5.25 \pm 0.25 b$ & $11.75 \pm 0.25 b$ \\
\hline $25: 16(21.25)$ & $2.75 \pm 0.48 a$ & $3.5 \pm 0.29 a$ & $4.75 \pm 0.25 \mathrm{ab}$ & $11 \pm 0.71 \mathrm{ab}$ \\
\hline $30: 10(21.67)$ & $2.5 \pm 0.29 a$ & $3 \pm 0.0 \mathrm{a}$ & $4.5 \pm 0.29 \mathrm{ab}$ & $9.75 \pm 0.48 a b$ \\
\hline $30: 13(22.91)$ & $2.5 \pm 0.29 a$ & $3 \pm 0.41 a$ & $4.5 \pm 0.29 \mathrm{ab}$ & $9.75 \pm 0.85 \mathrm{ab}$ \\
\hline $30: 16(24.17)$ & $2.25 \pm 0.25 a$ & $3 \pm 0.41 a$ & $3.5 \pm 0.29 a$ & $8.75 \pm 0.25 a$ \\
\hline
\end{tabular}

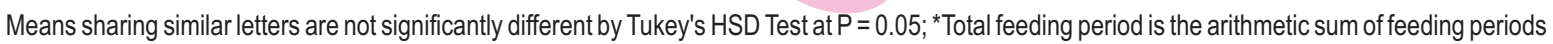
of third, fourth and fifth instar

days at $30: 16^{\circ} \mathrm{C}$ was close to the approximate digestibility values, $45.42 \%$ and $44.16 \%$ as reported by Dhandapani and Balasubramanian (1980) and Praveen and Dhandapani (2001), respectively on tomato crop under laboratory conditions. However, the range of approximate digestibility values (80.970$95.336 \%$ ) for whole larval instars reported by Kouhi et al. (2014) were higher than the values (8.675-46.298\%) presented in the current investigation. This inconsistency may have occurred as the present investigation is made on fresh weight basis under different alternating temperatures unlike the earlier experiment which had been carried out under constant temperatures on dry weight basis. Estimates of food utilization indices on fresh weight basis differ from those calculated on dry weight basis since the recorded percentage of dry matter of food, feces and insect differ (Waldbauer, 1968).In the present finding during fifth instar the approximate digestibility values increased from $19.952 \%$ at the lowest temperature $\left(25: 10^{\circ} \mathrm{C}\right)$ to $48.931 \%$ at the highest temperature of $30: 16^{\circ} \mathrm{C}$. This trend of approximate digestibility value increased with rising temperatures during final instar was consistent with the trend observed in the findings (33.43 to 47.54\%) of Karmakar and Pal (2017) in Spodoptera litura on tomato crop, when temperature rose from 20 to $25^{\circ} \mathrm{C}$ and also with the findings of Xiuzhen et al. (1990) in Mythimna separata. Interestingly, the decrease in approximate digestibility values was observed on transition of alternating temperature from $25: 16$ to $30: 10^{\circ} \mathrm{C}$ during fourth, fifth instars and total feeding period. This decreasing trend of approximate digestibility was found to be in agreement with the approximate digestibility (47.54 to $32.84 \%$ ) observed by Karmakar and $\mathrm{Pal}$ (2017) in S. litura on tomato crop from rising mean temperature from 25 to $30^{\circ} \mathrm{C}$. The rise and fall in the values of approximate digestibility can be attributed to the factors like food consumption and activity of digestive enzymes of insect which gets fluctuated by the rise and fall in temperature (Akbar et al., 2016; Dalal and Arora, 2016; Mohammadi et al., 2010; Kotkar et al., 2009). Hence, further investigation is required to understand the activity of larval digestive enzymes in relation to rise and fall of alternating temperatures.

Efficiency of conversion of ingested food into body substance : Efficiency of conversion of ingested food is an overall measure of an insect's ability to utilize ingested food for growth and development (Waldbaeur, 1968; Hemati et al., 2012; Kouhi et al., 2014). Earlier several studies were conducted to ascertain the suitable host of $H$. armigera for its growth and development on the basis of efficiency of conversion of ingested food values (Singh et al., 2008; Hemati et al., 2012; Kouhi et al., 2014). These studies concluded that host possessing higher conversion efficiency value is suitable to support the growth of the insect. Tomato possessing lower conversion efficiency value was recognised as unsuitable host for $H$. armigera (Hemati et al., 2012). Several factors presumed to affect the insect ability to utilize host which includes presence of allelochemicals and nutritional quality of host plant (Kouhi et al., 2014). Moreover, the presence of ortho-dihydroxy phenols and acidity in tomato fruit 
offers antibiotic resistance against $H$. armigera attack (Selvanarayanan and Narayanasami, 2006; Kashyap and Verma, 1987; Banerjee and Kalloo, 1989). As H. armigera larval development is temperature dependent and food consumption fluctuates with temperature change (Noor-UI-Ane 2017; Dalal and Arora 2016; Pandey et al., 2015). Hence, there is every possibility that the index of efficiency of conversion of ingested food, whose values depend on food consumption values, also get influenced by changing temperatures. However, some information is available in the literature on the impact of rising temperature on insect's ability to convert ingested food into body substance (Karmakar and Pal, 2017; Xiuzhen et al., 1990; Hegazi and Schopf, 1984). These studies concluded that conversion efficiency values decreased with increase in temperature from extremely low to moderate temperatures but further enhancement in temperature from moderate to extremely high temperatures leads to the attainment of higher values of conversion efficiency. However, reports on the impact of rise of alternating temperature on efficiency of conversion of ingested food values of $H$. armigera is meagre. Hence, the current study evaluated the impact of alternating temperatures on conversion efficiency which provided the preliminary information on temperature dependent changes in host suitability and insect's ability to convert ingested tomato fruit into body substance. The data on efficiency of conversion of ingested food into body substance at various alternating temperatures during third to fifth larval instars of $H$. armigera feeding on green tomato fruits are presented in Table 2. In the present study, under almost all alternating temperatures, except $25: 10^{\circ} \mathrm{C}$, efficiency of conversion of ingested food values declined with subsequent instars, however as per Scriber and Slansky (1981) conversion efficiency values may increase, decrease or show little change with subsequent instars. Changing efficiency of conversion of ingested food values with increasing instar level of $H$. armigera on tomato crop also suggests changes in nutritional requirement with the advancement of insect development (Kouhi et al., 2014). In this study, the highest mean values of efficiency of conversion of ingested food viz., 56.976, 43.983 and $10.527 \%$ were observed at mean alternating temperatures of $25: 13^{\circ} \mathrm{C}$ (third instar), $25: 10^{\circ} \mathrm{C}$ (fourth instar) and $30: 13^{\circ} \mathrm{C}$ (Fifth instar), respectively. At total feeding period (14.75 days), which is the sum of feeding period of three final instars (Table 3 ), the efficiency of conversion of ingested food was maximum $(14.993 \%)$ at the lowest alternating temperature $\left(25: 10^{\circ} \mathrm{C}\right)$ which declined gradually with rise in temperature to reach the minimum of $9.371 \%$ at the highest alternating temperature $\left(30: 16^{\circ} \mathrm{C}\right)$. The range of efficiency of conversion of ingested food values (9.371-14.993\%) for total larval period in this study was found to be close to the conversion efficiency values (11.535-15.985\%) recorded by Kouhi et al., (2014) on various cultivars of tomato crop. Similarly, conversion efficiency values of 16.33 and $9.51 \%$ reported by Praveen and Dhandapani (2001) and Dhandapani and Balasubramanian (1980) on tomato fruits, under laboratory condition, approaches the range of efficiency of conversion of ingested food values
(9.371-14.993\%) in the current study. The changing pattern of recorded conversion efficiency values in the present study with rise in mean temperature suggests that these values are affected by temperature fluctuation. Consequently, the lowest efficiency of conversion of ingested food values of $19.687,4.688$ and $9.371 \%$ during the third instar, fifth instar and total feeding period, respectively were recorded at the highest alternating temperature of $30: 16^{\circ} \mathrm{C}$. The trend of decreasing conversion efficiency values with increase in mean temperature in the present finding is in agreement with Karmakar and Pal (2017) who observed that the efficiency of conversion of ingested food values of last larval instar of $S$. litura on tomato crop decreased from 15.89 to $12.71 \%$ with increase in temperature from 20 to $25^{\circ} \mathrm{C}$ (Karmakar and Pal, 2017). Similarly, efficiency of conversion of ingested food value of M. separata decreased from $30.91 \%$ at $16^{\circ} \mathrm{C}$ to $22.72 \%$ at $20^{\circ} \mathrm{C}$ (Xiuzhen et al., 1990). However, a peculiar trend was observed in the efficiency of conversion of ingested food values between alternating temperatures $25: 16$ and $30: 10^{\circ} \mathrm{C}$. These values increased from $25: 16$ to $30: 10^{\circ} \mathrm{C}$ during all the instars and total feeding period. This trend was found to be in conformity with the results of $S$. litura on tomato, castor and cabbage crops, when constant temperature increased from 25 to $30^{\circ} \mathrm{C}$ (Karmakar and $\mathrm{Pal}, 2017)$. Conversion efficiency values of last larval instar of $S$. littoralis on semi-artificial diet also rose from $13.4 \%\left(25^{\circ} \mathrm{C}\right)$ to $18.0 \%\left(30^{\circ} \mathrm{C}\right)$ unlike the decline in same values from 20 to $25^{\circ} \mathrm{C}$ (Heghazi and Schopf, 1984). So it can be concluded that in the event of simultaneous rise in maximum temperature and decrease in minimum temperature there is an increase in $H$. armigera efficiency to convert food into body substance which makes tomato fruit more suitable host. It can be inferred from this study that apart from development and food consumption of an insect, host suitability is also temperature dependent. Any host which is designated as unsuitable or resistant against insect herbivore may become susceptible with fluctuations in the ambient temperature regimes.

\section{Acknowledgment}

Authors express gratefulness to the Indian Council of Agricultural Research (ICAR) for financially supporting this research through junior research fellowship.

\section{References}

Akbar, S.M., T. Pavani, T. Nagaraja and H.C. Sharma: Influence of $\mathrm{CO}_{2}$ and temperature on metabolism and development of Helicoverpa armigera (Noctuidae: Lepidoptera). Envir. Ent., 45, 229-236 (2016).

Anonymous: Package of Practices for Cultivation of Vegetables. Punjab Agricultural University, Ludhiana, Punjab, India (2013).

Ansari, M.S., F. Hasan and N. Ahmed: Influence of various host plants on the consumption and utilization of food by Pieris brassicae (Linn.). Bull. Ent. Res., 102, 231-237 (2012).

Armes, N.J., G.S. Bond and R.J. Cooter: The Laboratory Culture and Development of Helicoverpa armigera. Natural Resource Institute Bulletin 57, NRI, Chatham, UK (1992). 
Arora, R. and G.S. Battu: An inexpensive oviposition cage for Helicoverpa armigera (Hubner), Ann. PI. Prot. Sci., 4, 169-170 (1996).

Ayers, M.P. and J.M. Scriber: Local adaptation to regional climates in Papilio canadensis (Lepidoptera: Papilionidae). Ecol. Monogr., 64, 465-482 (1994).

Banerjee, M. K. and G. Kalloo: Role of phenols in resistance to tomato leaf curl virus, Fusarium wilt and fruit borer in Lycopersicon. Curr. Sci. 58, 575-576 (1989).

Bhat, N.S. and A.K. Bhattacharya: Consumption and utilization of soybean by Spodoptera litura (Fabricius) at different temperatures. Indian. J. Ent., 40, 16-25(1978).

Dalal, P. K. and R. Arora: Impact of temperature on food consumption and nutritional indices of tomato fruit borer, Helicoverpa armigera (Hubner) (Noctuidae: Lepidoptera). J. Agromet., 18, 62-67 (2016).

Dhandapani, N. and M. Balasubramanian: Consumption and utilization of different food plants by Heliothis armigera (Hubner) (Noctuidae: Lepidoptera). Entomon., 5, 99-102 (1980).

Fitt, G.P.: The ecology of Heliothis armigera species in relation to agroecosystem. A. Rev. Ent., 34, 17-52 (1989).

Hegazi, E. M. and R. Schopf : The influence of temperature on consumption and utilization of artificial diet by Spodoptera littoralis (Boisd.) (Lepidopt., Noctuidae). Z. Ang. Ent., 97, 321-326 (1984).

Hemati, S. A., B. Naseri, G. N. Gaubalani, H. F. Dastjerdi and A. Golizadeh: Effect of different host plants on nutritional indices of the pod borer, Helicoverpa armigera. J. Insect. Sci. 12, (2012). doi: 10.1673/031.012.5501.

IPCC: Climate Change: Synthesis Report. Contribution of Working Groups I, II and III to the Fifth Assessment Report of the Intergovernmental Panel on Climate Change (Eds.: R.K. Pachauri and L.A. Meyer). IPCC, Geneva, Switzerland (2014).

Karmakar, P. and S. Pal: Influence of temperature on food consumption and utilization parametres of common cutworm, Spodoptera litura (Fab.) (Lepidoptera: Noctuidae). J. Ent. Zoo. Stud., 5, 92-95 (2017).

Kashyap, R. K. and A. N. Verma: Factors imparting resistance to fruit damage by Heliothis armigera (Hubner) in some tomato genotypes. Insect Sci. Appl., 8, 111-114 (1987).

Kaur, P., H. Singh, A. Singh, S.K. Bal and S.S. Sandhu: Variability trends in meteorological parameters at Ludhiana. J. Res. Punjab. Agric. Univ., 49, 17-23 (2012)

Kotkar, H. M., P. J. Sarate, V. A. Tamhane, V. S. Gupta and A. P. Giri: Responses of midgut amylases of Helicoverpa armigera to feeding on various host plants. J. Insect. Physiol., 55, 663-670 (2009).

Kouhi, D., N. Bahram, and A. Golizadeh: Nutritional performance of the tomato fruit borer, Helicoverpa armigera, on different cultivars. J. Insect. Sci., 14, (2014). doi: 10.1093/jis/14.1.102.

Kriticos, D.J., N. Ota, W.D. Hutchison, J. Beddow, T. Walsh, W.T. Tay, D.M. Borchert, S.V. Paula-Moreas, C. Czepak and M.P. Zalucki: The potential distribution of invading Helicoverpa armigera in North America: Is it just a matter of time?. PLoS. One, 10, (2015). doi: 10.1371/journal. pone. 0133224 .

Manjunath, T.M., V.S. Bhatnagar, C.S. Pawar and S. Sithanantham: Economic importance of Heliothis spp. in India and an assessment of their natural enemies and host plants. In: Proceedings of Workshop on Biological Control of Heliothis: Increasing the Effectiveness of Natural Enemies., New Delhi, India, p. 197-228 (1989).

Meena, L. K. and S. V. S. Raju: Bioefficacy of newer insecticides against tomato fruit borer, Helicoverpa armigera (Hubner) on tomato,
Lycopersicon esculentum mill under field conditions. The. Bioscan, 9, 347-350 (2014).

Mohammadi, D., R.F.P. Abad, M. R. Rashidi and S. A. Mohammadi: Activity and some properties of Helicoverpa armigera Hubner and Spodoptera exigua Hubner (Lep.: Noctuidae) on midgut protease. Mun. Ent. Zool.., 5, 697-706 (2010).

Noor-ul-Ane, M., M. A. Mirhosseini, N. Crickmore, S. Saeed, I. Noor and M. P. Zalucki.: Temperature-dependent development of Helicoverpa armigera (Hübner) (Lepidoptera: Noctuidae) and its larval parasitoid, Habrobracon hebetor (Say) (Hymneoptera: Braconidae): Implications for species interactions. Bull. Ent. Res. (2017). doi:10.1017/S0007485317000724.

O'Connor, M.l.: Warming strengthens an herbivore-plant interaction. Ecology, 90, 388-398 (2009).

Pandey, S., S. Sharma, S. S. Sandhu and R. Arora: Development and food consumption of some lepidopteran pests under increased temperature conditions. J. Agromet., 17, 36-42 (2015).

Paul, A.V.N., R. Dass and B. Prasad: Sex determination of pupae of Heliothis armigera on gram. Indian J. Ent., 41, 285 (1979).

Praveen, P.M. and N. Dhandapani: Consumption, digestion and utilization of biopesticides treated tomato fruits by Helicoverpa armigera (Hubner). J. Biol. Control., 15, 59-62 (2001).

Rabindra, R.J., S.R. Philip, P.C. Sundarababu and M. Gopalan: Technology for mass production of biopesticides. Center for Plant Protection Studies, Tamil Nadu Agricultural University, Coimbatore (1997).

Scriber, J.M. and F. Slansky: The nutritional ecology of immature insects. A. Rev. Ent., 26, 183-211 (1981).

Selvanarayanan, V. and P. Narayanasami: Factors of resistance in tomato accessions against fruit worm, Helicoverpa armigera (Hubner). Crop. Prot. 25, 1075-1079 (2006).

Sidhu, J.K and R.Arora: Studies on host plant suitability of selected rabi forage legumes for gram caterpillar Helicoverpa armigera (Hubner). J. Res. Punjab. Agric. Univ., 48, 140-48 (2011).

Singh, B., A. Kumar and G. P. Gupta: Nutrional indices for Helicoverpa armigera (Hubner) on different host plants. Indian J. Ent., 70, 237240 (2008).

Singh, N., S.K. Dostasara, S.M. Jat and A.R. Naqvi.: Assesment of crop losses due to tomato fruit borer, Helicoverpa armigera in tomato. J. Ent. Zoo. Stud., 5, 595-597 (2017).

Slansky, F.: Insect nutritional ecology as a basis for studying host plant resistance. Flor. Entomol., 73, 359-378 (1990).

Soo Hoo, C.F. and G. Fraenkle: The consumption, digestion and utilization of food by phytophagous insects Prodenia eridania (Cramer). J. Insect Physiol., 12, 711-30 (1966).

Tay, W.T., M.K. Soria, T. Walsh, D. Thomazani, P. Silvie, G.T. Behere, C. Anderson and S. Downes.: A brave new world for an old world pest: Helicoverpa armigera (Lepidoptera: Noctuidae) in Brazil. PLoS. One, 8 (2013). (doi:10.1371/journal.pone.0080134).

Waldbauer, G.P.: The consumption and utilization of food by insects. Adv. Insect Physiol., 5, 229-282 (1968).

Xiuzhen, L., W. Kunjun and G. Peiyu: Effect of temperature on population growth and intake of food by armyworm Mythimna separata (Walker). J. Environ. Sci., 2, $39-44$ (1990).

Yuan, J. S., S.J. Himanen, J.K. Holopainen, F. Chen and C.N. Stewart: Smelling global climate change: Mitigation of function for plant volatile organic compounds. Tren. Ecol. Evol., 24, 323-331 (2009). 